\title{
Principais técnicas para a reutilização de pneus inservíveis no Brasil
}

\section{Júlia Rélene de Freitas Rodrigues* e Letícia Gabriele da Silva Bezerra}

Universidade do Estado do Rio Grande do Norte. Programa de Pós-Graduação em Ciências Naturais - Nível Mestrado. Campus Central. Avenida Professor Antônio Campos, S/№. Presidente Costa e Silva. Mossoró-RN, Brasil (CEP 59610-210). *E-mail: juliarelene@gmail.com.

Resumo. 0 descarte adequado de resíduos sólidos é uma das grandes preocupações ambientais no mundo, a exemplo devido à quantidade crescente de veículos no Brasil a geração de pneus inservíveis passa a ser preocupante, por isso este trabalho tem como objetivo geral analisar as principais técnicas para reutilização de pneus inservíveis no Brasil. As principais técnicas de reutilização de pneus inservíveis no Brasil foram identificadas a partir da pesquisa bibliográfica. Os resultados elencaram as técnicas de composição de concreto, composição de argamassa de cimento e cal, asfalto borracha, coprocessamento, laminação, granulação/trituração, pirólise e contenção de erosão dos solos como as mais usuais, listando também suas principais vantagens. Logo, este ensaio visa a colaborar para propagação das principais técnicas de reutilização de pneus inservíveis no Brasil, visando à sustentabilidade tão necessária à sociedade.

Palavras-chave: Sustentabilidade; Tecnologia verde; Logística reversa; Resíduos sólidos; Reciclagem.

\begin{abstract}
Main techniques for reusing waste tires in Brazil. The proper disposal of solid waste is one of the major environmental concerns in the world, for example, due to the growing number of vehicles in Brazil, the generation of waste tires becomes a concern, so this paper aims to analyze the main techniques for reusing waste tires in Brazil. The main techniques for reusing waste tires in Brazil were identified from the bibliographical research. The results listed the most usual techniques of concrete composition, cement and lime mortar composition, rubber asphalt, co-processing, lamination, granulation/crushing, pyrolysis and soil erosion containment, also listing their main advantages. Therefore, this essay aims to contribute to the propagation of the main techniques for reusing waste tires in Brazil, aiming at the sustainability that is so necessary for society.
\end{abstract}

Keywords: Sustainability; Green technology; Reverse logistic; Solid waste; Recycling.
Recebido

28/08/2021

Aceito

$27 / 11 / 2021$

Disponível on line 28/11/2021

Publicado

$31 / 12 / 2021$

Acesso aberto

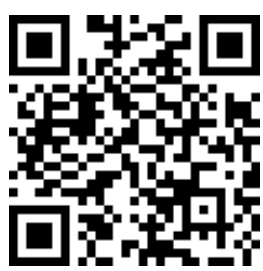

\footnotetext{
ORCID

(ㄱ) 0000-0003-1853-3799 Júlia Rélene de Freitas Rodrigues

D 0000-0003-1026-7289

Letícia Gabriele da Silva Bezerra
}

ISSN 2359-1412/RBGAS-2021-0110/2021/8/20/10/1407 


\section{Introdução}

Um dos maiores desafios da sociedade atual é alcançar a tão referida sustentabilidade, sendo necessárias mudanças que abarquem os eixos ambiental, social e econômico para tornar essa premissa possível. Nesse sentido, os resíduos sólidos apresentam-se como um dos principais problemas a serem enfrentados. De acordo com a norma ABNT NBR 10004:2004 (ABNT, 2004), são considerados os resíduos sólidos os:

Resíduos nos estados sólido e semi-sólido, que resultam de atividades de origem industrial, doméstica, hospitalar, comercial, agrícola, de serviços e de varrição. Ficam incluídos nesta definição os lodos provenientes de sistemas de tratamento de água, aqueles gerados em equipamentos e instalações de controle de poluição, bem como determinados líquidos cujas particularidades tornem inviável o seu lançamento na rede pública de esgotos ou corpos de água, ou exijam para isso soluções técnica e economicamente inviáveis em face a melhor tecnologia disponível (ABNT, 2004, p. 1).

Somente a partir da década de 1970 as questões ambientais passaram a ser visadas no mundo e creditadas como questões importantes, visando a mudanças necessárias. Até então, e infelizmente ainda muito presente, o crescimento e desenvolvimento dos países, estava associado à sua quantidade produtiva. Atrelado a essa questão, pode-se inserir a produção, utilização e descarte dos pneus, os quais, desde sua popularização em meados do século XIX, estão sendo cada vez mais utilizados, trazendo consigo certa preocupação no viés do descarte (Ribeiro, 2016; Araújo, 2018). Por isso, Bernardo (2017) discute que a reciclagem e o reaproveitamento são a saída para esquivarse dessa situação.

Em 2019, foi divulgado um estudo referente ao mapa de motorização individual no Brasil, com base entre 2008 e 2018, onde foi levantado um total de automóveis no Brasil que passou de 37,1 milhões em 2008 para 65,7 milhões em 2018. Sendo as 17 principais regiões metropolitanas do país responsáveis por $40 \%$ desse crescimento (Rodrigues, 2019), em suas palavras, "[...] as cidades que enfrentam os piores problemas de trânsito e transporte continuam recebendo boa parte da carga de novos automóveis que passaram a povoar as ruas nos últimos anos" (Rodrigues, 2019). Esse aumento traz consigo várias preocupações, entre elas, o que pode ser feito com os pneus inservíveis gerados por esses diversos veículos que circulam no país, assim como também existe a geração de pneus provenientes de motocicletas e bicicletas.

Os pneus inservíveis são uma das classificações que pode ser dada a esse material, onde Araújo (2018) define os pneus inservíveis como aqueles que não possuem mais nenhuma possibilidade de recauchutagem ou recapagem, ou seja, não servem mais para sua finalidade original. No Brasil e no mundo, existe uma grande quantidade de descarte desses pneus e isso se constitui cada vez mais como um problema ambiental, mediante sua composição, durabilidade, volume e compressibilidade.

Ainda de acordo com Araújo (2018), uma vez descartados no meio ambiente, os pneus são potencialmente impactantes, poluindo solos, águas, ar, mares e não menos importante, favorecem problemas de saúde pública, uma vez que, quando descartados inadequadamente podem acumular água, favorecendo a proliferação do mosquito Aedes aegypti, transmissor da dengue, zika e chikungunya. Nesse mesmo viés, Henkes e Rodrigues (2015), reforçam que o descarte inadequado dos pneus gera problemas ao meio ambiente e à saúde pública. 
Numa busca para minimizar essa problemática do descarte de pneus, principalmente os inservíveis, projetos vem sendo desenvolvidos em busca de sua reutilização. Já na década de 1960, nos Estados Unidos, buscaram-se desenvolver uma nova mistura na composição das bases asfálticas, com o uso do "asfalto borracha", todavia, com alto custo de produção o que não permitiu sua utilização em larga escala. No final da década de 1990 esse projeto foi retomado pela Universidade do Rio Grande do Sul junto com uma produtora de asfalto, uma vez que já existiam novas tecnologias, diminuindo os custos e ampliando a produção de asfalto borracha ou asfalto ecológico, como levantam Henkes e Rodrigues (2015).

Atualmente, após diversos estudos e experimentos, é verificado que os pneus, ao final de sua vida útil, podem ser utilizados como combustível alternativo e, quando reciclados, podem ser transformados em tapetes para automóveis, solado de sapato, pisos industriais, pisos de quadras esportivas, borrachas de vedação, entre outros usos. 0 pó gerado na recauchutagem e seus restos moídos também podem ser usados na composição de asfalto de maior elasticidade e durabilidade (Araújo, 2018).

Não menos importante, Araújo (2018), discute que o coprocessamento, ou seja, a utilização dos pneus inservíveis como combustível alternativo em fornos de cimento, tem sido a alternativa de destinação mais buscada no Brasil e em outros países. Uma vez que esse processo proporciona o aproveitamento térmico e a valorização energética deste resíduo, o que reduz o uso de combustíveis fósseis não-renováveis. Além disso, o aço contido nos pneus e as cinzas resultantes da queima podem ser incorporados ao cimento (Araújo, 2018).

É de suma importância alterar a visão sobre os pneus, pois estes podem substituir materiais limitados e esgotáveis, amenizando assim custos financeiros, desequilíbrio ambiental e perda de pneus. Sua reutilização pode ser feita por separação de componentes, trituração ou ser usado de forma inteira. Esse material tem ganhado destaque, como discorre Barros e Pastor (2019), uma vez que pode ser usado de várias formas, como: aterros ou suporte de estradas, material para compostagem, barragens, isolantes térmicos e acústico, aditivo para pavimento asfáltico e até estabilizadores de encostas.

Em vista dos argumentos apresentados, este trabalho tem como objetivo geral analisar as principais técnicas para reutilização de pneus inservíveis no Brasil a partir da pesquisa bibliográfica. A seguir, se encontra os procedimentos metodológicos realizados para concretizar o objetivo do trabalho. Os resultados estão estruturados em três tópicos, os dois primeiros discorrem sobre a sustentabilidade inserida na reutilização e reciclagem de pneus e a importância da logística reversa de pneus pode evitar o descarte irregular do mesmo no meio ambiente, diminuindo a poluição e os efeitos prejudiciais à saúde pública, em seguida são elencadas as principais técnicas de reutilização de pneus do Brasil junto as vantagens atreladas a cada uma das técnicas. E por fim, no último tópico se encontram as considerações finais do trabalho.

\section{Metodologia}

Como procedimento técnico para concretização do objetivo da pesquisa utilizou-se exclusivamente da pesquisa bibliográfica. Além da aproximação com a temática e redação deste artigo, a pesquisa bibliográfica foi fundamental para identificar as principais técnicas de reutilização de pneus inservíveis no Brasil, elencados a partir da leitura em importantes materiais já publicados, assim como para auxiliar nesta identificação, pesquisou-se sobre as técnicas que vem sendo discutidas em publicações realizadas em revistas científicas, cabe destacar que o propósito desta identificação não foi o de elaborar uma análise bibliométrica da temática, mas sim de obter um panorama geral das técnicas de reutilização de pneus inservíveis mais utilizadas no país. 
Para tanto, a busca pelas publicações foi realizada em três relevantes plataformas de base de dados, Google Scholar, Portal periódicos da Coordenação de Aperfeiçoamento de Pessoal de Nível Superior (CAPES) e Scientific Electronic Library Online (SCIELO Brazil). Nestas plataformas foi buscado pela palavra-chave entre aspas "reutilização de pneus inservíveis" junto ao filtro data de publicação para os últimos cinco anos (2017-2021), tendo em vista a atualização sobre a temática. A busca também se restringiu a apenas artigos científicos publicados em revistas brasileiras:

No Google Scholar foram identificados 39 resultados pela palavra-chave e data de publicação, estes tiveram seus títulos, resumos e palavras-chaves lidos, selecionando-se apenas nove resultados, devido ao critério de seleção de publicações em revistas científicas brasileiras e que tratassem da discussão de alguma técnica de reutilização de pneus inservíveis. Usando-se dos mesmos critérios foi encontrado e selecionado apenas um resultado no Portal de Periódicos da CAPES, não sendo encontrado nenhum resultado na SCIELO Brazil.

Com a obtenção dos dez resultados, estes novamente foram lidos e categorizados pelas técnicas empregados na reutilização de pneus inservíveis, apoiando na escolha das técnicas analisadas neste trabalho.

\section{Resultados e discussão}

\section{Sustentabilidade: discutindo sobre a reutilização e reciclagem de pneus}

Desde o surgimento da ideia de Desenvolvimento Sustentável, como um modelo econômico, político, social, cultural e ambiental equilibrado, que satisfaça as necessidades das gerações atuais, sem comprometer a capacidade das gerações futuras de satisfazer suas próprias necessidades, a sociedade passou a integrar-se mais nas causas ambientais (Sachs, 2004). Enquanto que a sustentabilidade, para Boff (2017), vem em um sentido de tentativa de conscientizar a sociedade da importância da preservação do meio ambiente, aliado a um processo de produção eficiente com responsabilidade ambiental e não menos importante, suprindo com as necessidades financeiras das empresas.

Nesse sentido, se faz necessário dialogar sobre a sustentabilidade empresarial, essa tem a capacidade de mudar de forma positiva a imagem de uma empresa junto aos consumidores, principalmente quando correlacionado com o aumento dos problemas ambientais gerados pelo crescimento desordenado nas últimas décadas, pois os consumidores estão cada vez mais conscientes da importância da defesa do meio ambiente (Barros e Pastor, 2019). Barros e Pastor (2019) ainda comentam sobre as vantagens dessas novas práticas empresariais que vão além de melhorar a imagem da empresa perante a sociedade, como para a economia, com redução de custos na produção; satisfação dos funcionários e colaboradores, através da consciência ambiental; e valorização das ações em bolsas de valores, pois a sustentabilidade é um dos quesitos buscados nas atuais companhias.

Em Henkes e Rodrigues (2015) é discutida que a ideia de reutilização de pneus é antiga, todavia esse avanço se deu durante a Segunda Guerra Mundial, decorrente da dificuldade em obter a matéria-prima para fabricação de novos pneus. Além disso, o autor ressalta que a correta destinação final do pneu após sua vida útil deve ser algo seguido por todos, desde os consumidores, fabricantes e importadores de pneus, a fim de preservar o meio ambiente e a saúde pública, aliados à economia de matéria prima utilizada na confecção de pneus novos (Henkes e Rodrigues, 2015).

Portanto, a reciclagem e a reutilização de pneus além de contribuir para a preservação ambiental, em alguns casos, se não todos, é uma boa alternativa financeira às empresas, em especial ao setor de construção civil, pois produtos derivados dos pneus podem substituir outras matérias primas. Portanto, o viés da sustentabilidade pode e deve ser consolidado na reutilização e reciclagem deste material. 


\section{Logística reversa e os pneus inservíveis}

A logística reversa surge no sentido de aplicar-se e controlar-se com eficiência, para proporcionar ganhos ao meio ambiente, como a redução dos impactos ambientais e menor extração de recursos naturais, e às empresas, por meio da redução de alguns custos e melhora significativa de sua imagem corporativa perante a sociedade (Ribeiro, 2016).

Por isso, o desenvolvimento de um sistema nesse sentido, de forma independente do serviço público de limpeza urbana e de manejo dos resíduos sólidos, tornou-se obrigatório para fabricantes, distribuidores e importadores a partir da aprovação da Política Nacional de Resíduos Sólidos (PNRS), em 2 de agosto de 2010 (Brasil, 2010). Todavia, a logística reversa já era exigida pela Resolução CONAMA no 418/2009 (Brasil, 2009), porém não previa a retirada de pneus inservíveis, como traz Araújo (2018). Esses se caracterizavam como passivos ambientais, em aterros, lixões, rios, terrenos baldios e outros.

Para tanto, ainda são corriqueiras diversas dificuldades da logística reversa para com pneus, como apresenta a Associação Nacional da Indústria de Pneumáticos (ANIP, 2015), uma vez que é um produto volumoso e pesado, cujo transporte é concentrado no modal rodoviário, trazendo em todo o ciclo um custo significativo para a indústria, desde a matéria-prima ao inservível descartado, agravado pelos custos relacionados à logística brasileira, como impostos sobre o frete, taxas de pedágio, alto índice de roubo de carga e qualidade das estradas brasileiras, que tornam o produto ainda menos competitivo. Atrelado ao descumprimento por parte dos importadores, de acordo com as metas anuais estabelecidas pelo Instituto Brasileiro do Meio Ambiente e dos Recursos Naturais (IBAMA) (ANIP, 2015).

Todavia, conforme relatado no Relatório IBAMA de Pneumáticos (Sousa, 2021), os fabricantes de pneus novos alcançaram $101,72 \%$ da meta de destinação estabelecida para o ano de 2019, enquanto os importadores cumpriram com $85,92 \%$ de sua meta estipulada. De acordo com os dados apresentados no referido relatório, a Região Nordeste está em quarto lugar $(7,32 \%)$, entre as cinco regiões brasileiras, no que se refere à quantidade de pneus inservíveis destinados, sendo a região sudeste a líder nesse ranking, com 53,14\% (Sousa, 2021).

É de suma importância citar o conceito de pneus inservíveis, onde Sousa (2021) o considera como o pneu pós-uso que apresenta danos irreparáveis em sua estrutura, não se prestando mais à rodagem ou à reforma. Enquanto a destinação ambientalmente adequada de pneus inservíveis é:

\footnotetext{
Procedimentos técnicos em que os pneus são descaracterizados de sua forma inicial, e que seus elementos constituintes são reaproveitados, reciclados ou processados por outra(s) técnica(s) admitida(s) pelos órgãos ambientais competentes, observando a legislação vigente e normas operacionais específicas, de modo a evitar danos ou riscos à saúde pública e à segurança, e a minimizar os impactos ambientais adversos (Sousa, 2021, p. 11).
}

Em 2007 foi criada a RECICLANIP, um eixo da ANIP próprio para ações de reciclagem, reutilização, entre outras vertentes que contemplem o ciclo sustentável do pneu, cujo sua missão "é ser uma entidade-modelo, autossustentável, reconhecida e admirada pelo trabalho efetivo na destinação de pneus inservíveis e dotada de autonomia operacional e financeira" (RECICLANIP, 2019a), sendo uma referência mundial em logística reversa.

\section{Reutilização dos pneus inservíveis no Brasil}

A seguir, na Figura 1, se encontra as principais técnicas de reutilização de pneus inservíveis no Brasil identificados a partir da busca realizada em três relevantes 
plataformas de base de dados, lembrando que essa pesquisa foi realizada seguindo alguns critérios que se encontram descritos na metodologia.

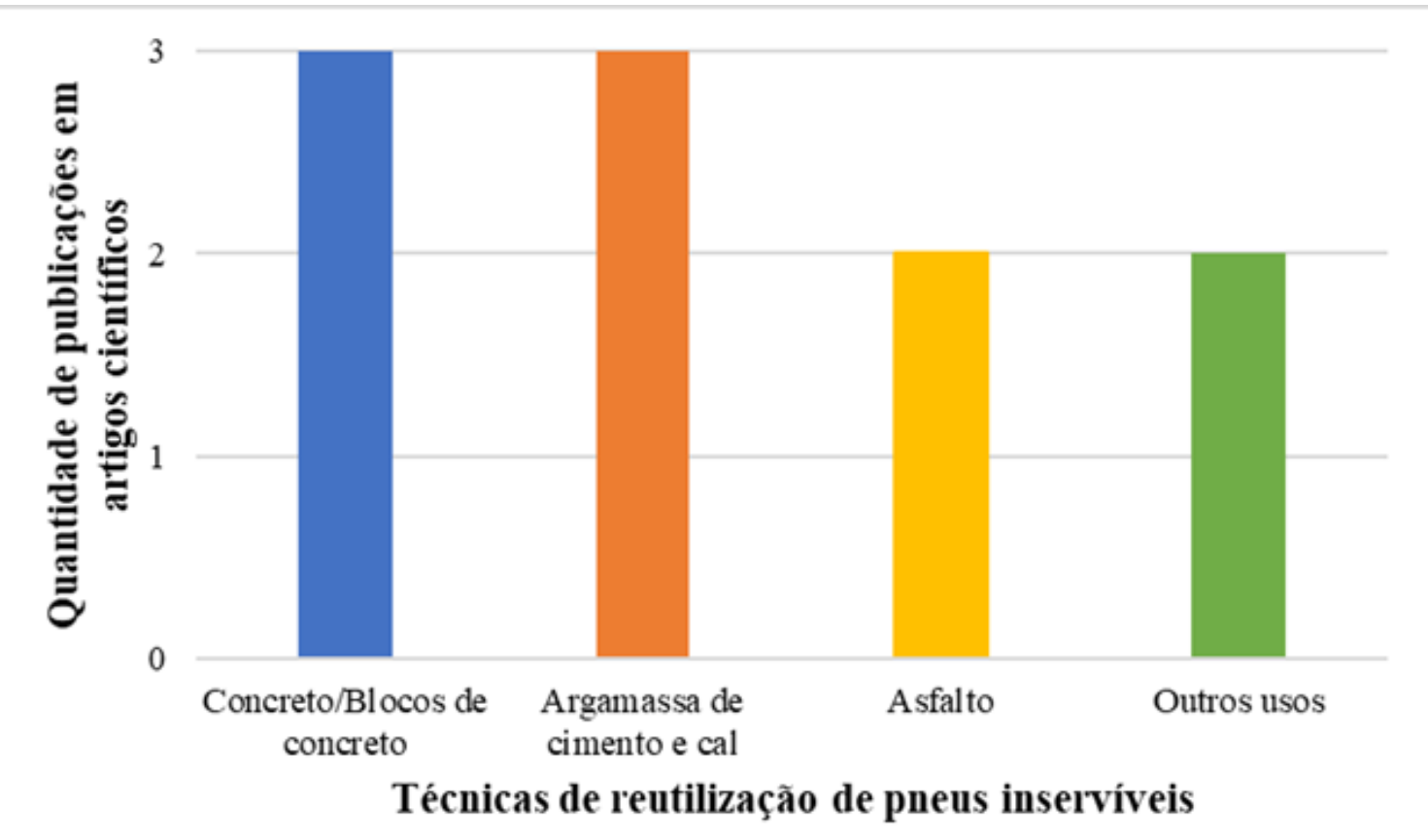

Figura 1. Principais técnicas de reutilização de pneus inservíveis no Brasil (2017-2021).

Dos dez trabalhos identificados, três discorrem sobre a reutilização de pneus inservíveis como concreto/bloco de concreto para utilização como piso intertravados para calçadas, guias sarjetas e mobiliários urbanos, três discorrem sobre a utilização em argamassa seja de cimento ou cal, dois sobre a reutilização em asfalto, e outros dois classificados como "outros usos" se referem a utilização em painéis aglomerados e como isolante térmico, conforme Figura 1.

Além desses dados, com a realização da leitura de materiais que não foram identificados pela palavra-chave utilizada, foram identificadas outras técnicas de reutilização usuais, pois após muitas pesquisas e cooperação entre os setores de educação, empresarial e outros, é possível elencar diversas áreas onde é feito a reutilização dos pneus inservíveis, tais como coprocessamento, laminação, granulação, pirólise, contenção de erosão dos solos e etc. (Hankes e Rodrigues, 2015; RECICLANIP, 2019b; Sousa, 2021).

\section{Composição de concreto}

Na composição de concreto utiliza-se raspas de pneus como agregado reciclado em substituição ao agregado graúdo convencional, como mencionado por Romualdo et al. (2011). Tem sua justificativa pautada em assumir um papel importante na preservação do meio ambiente, pois, além de diminuir a extração de recursos naturais, como a areia e a brita, também pode diminuir o acúmulo desses resíduos nas áreas urbanas.

Ao conter $4 \%$ de borracha de pneus inservíveis no concreto, aumenta a vida útil das calçadas, reduz o montante de resíduos de pneus no meio ambiente, principalmente nos aterros sanitários e a quantidade de areia explorada para este uso, além de que o concreto permite grande variabilidade de formas e de concepções, configurando nas 
principais vantagens de utilizar pneus na composição do concreto (Romualdo et al., 2011; Rabelo, 2017).

\section{Composição de argamassa de cimento e cal}

Semelhante ao concreto, a utilização da borracha de pneus inservíveis na argamassa cimento e cal se dá pela substituição parcial do agregado miúdo (areia). Kurz et al. (2018a) e Kurz et al. (2018b) apontam que apesar da mudança de comportamento em argamassas com a substituição parcial da areia pela borracha, os resultados estão de acordo com os estipulados pelas norma da ABNT. Esse potencial de utilização reduz a quantidade de resíduos de pneus inservíveis descartados e a retirada da areia, um recurso natural, do meio ambiente (Kurz et al., 2018b).

\section{Asfalto borracha}

0 asfalto borracha é a adição à massa asfáltica de pó de borracha oriundo da trituração de pneus inservíveis. Dentre suas vantagens, pode-se destacar: uma vida útil maior, diminuição dos custos de conservação, por envelhecer menos durante a usinagem e suportar maior deformação, aumentando assim a durabilidade do revestimento; diminuição dos intervalos de interrupção de pista para reparos de conservação e mesmo restauração; menor espessura de pista de rolamento, diminuindo assim redução de esforço nos acostamentos; economia de combustível durante a usinagem e transporte de massa asfáltica, diminuição de tempo para executar a obra prevista, além de gerar um nível de ruído menor, oferece maior segurança aos usuários das rodovias, proporcionando um retardo na propagação de trincas, redução da espessura da camada aplicada, e também a redução de manutenção do pavimento. Entretanto, ainda apresenta-se $30 \%$ mais cara do que comparado aos materiais convencionais (Hankes e Rodrigues, 2015; RECICLANIP, 2019b; Vucovic, 2021).

Vucovic (2021) informa que nos Estados Unidos e outros países desenvolvidos, a utilização do asfalto borracha já vem sendo empregada em projetos para a recuperação da eficiência estrutural de pavimentos degradados e na formação de novas camadas de pavimentos, além de serviços de manutenção corretiva. Já em cenário nacional, apesar da primeira aplicação desse material ser datado em 2001, ainda não se popularizou. Todavia vem apresentando um aumento de interesse visto seu custo-benefício.

Hankes e Rodrigues (2015) ressaltam que o Brasil possui uma demanda muito grande de implantação e recapeamento de rodovias pavimentadas. Onde o fator principal pode estar relacionado a extensa malha rodoviária e ao número considerável de caminhões pesados e ônibus que fazem o transporte de mercadorias e pessoas diariamente em nosso país, podendo ser empregado a utilização do asfalto borracha.

\section{Coprocessamento}

Coprocessamento é o procedimento de utilizar os pneus inservíveis em fornos de clínquer como substitutos parciais de combustíveis e como fontes de elementos metálicos, pois com seu alto poder calorífico cerca de $70 \%$ dos pneus inservíveis são utilizados como combustível alternativo em fornos de cimenteiras, em substituição ao coque de petróleo, além de amenizar o custo do processo (RECICLANIP, 2019b; Sousa, 2021).

As vantagens na utilização dos pneus inservíveis em relação aos combustíveis tradicionais aparecem no sentido de gerar menos dióxido de enxofre $\left(\mathrm{SO}_{2}\right)$ na atmosfera, redução do custo de produção do cimento, menor formação de dioxinas devido ao elevado tempo de residência em um ambiente alcalino e com presença de sulfatos, característicos do processo de produção do cimento (Araujo, 2020).

No entanto Araújo (2018) chama atenção no viés ambiental comentando que apesar do coprocessamento de pneus inservíveis ser uma alternativa de eliminação de resíduos de grandes volume e peso que poderiam ter destinação de maior impacto 
ambiental, como a disposição em aterros, os fatores legais devem ser observados, uma vez que são liberados gases nocivos, como monóxido de carbono (CO) na atmosfera.

No tocante a legislação, a Resolução CONAMA no 499/2020, dispõe sobre o licenciamento da atividade de coprocessamento de resíduos em fornos rotativos de produção de clínquer. Nela estão estabelecidos os critérios básicos, limites máximos de emissão atmosférica de alguns poluentes para essas atividades, procedimentos para o licenciamento ambiental e outros conteúdos necessários para execução da atividade (Brasil, 2020).

\section{Laminação}

A laminação é caracterizada como o processo de fabricação de artefatos de borracha (Sousa, 2021). Nesse processo, o RECICLANIP (2019b) informa que os pneus não-radiais são cortados em lâminas que servem para a fabricação de percintas, solas de calçados, dutos de águas pluviais, etc. Nerasti e Martins (2017) discutem que ao final do processo de laminação, as sobras de pneus são destinadas para outros processos de reciclagem, em especial a trituração para produção de grânulos de borracha.

Nerasti e Martins (2017) também comentam sobre as vantagens desse processo, citando ser uma tecnologia de baixo custo, apresentando um baixo valor de implementação e operação; apresentam diversos usos, tornando-se matéria prima para muitas indústrias, tais como: indústria de calçados, solados, revestimento de quadras de esportes, revestimento para escadarias e pisos, tiras para sofás, poltronas e móveis, fábricas de rodo, produção de chinelos, construção civil, entre outros.

\section{Granulação/trituração}

A granulação ou trituração é o processo industrial de fabricação de borracha moída, em diferente granulometria, com separação e aproveitamento do aço (Sousa, 2021). Esse processo de trituração à temperatura ambiente é relativamente simples, como informam Nerasti e Martins (2017), todavia esse procedimento tem a desvantagem de ser viável somente quando realizada em grandes quantidades, uma vez que os equipamentos são caros e requerem mão de obra para a operação e manutenção preventiva (Nerasti e Martins, 2017).

\section{Pirólise}

Pirólise é o processo de decomposição térmica da borracha conduzida na ausência de oxigênio ou em condições em que a concentração de oxigênio é suficientemente baixa para não causar combustão, com geração de óleos, aço e negro de fumo (Sousa, 2021). Schwalm et al.(2020) ressaltam que no processo de pirólise de pneus são obtidos produtos que podem ser utilizados em diversas aplicações, por isso a pirólise de resíduos de pneus pode ser usada como uma solução alternativa de gerenciamento de resíduos e produção de energia renovável.

Porém, em nível nacional, a pirólise de pneus ainda não é uma tecnologia consolidada. Para Schwalm et al. (2020) são muitas as dificuldades encontradas, desde barreiras tecnológicas, econômicas e legais que desencorajam a aceitação dessa tecnologia pelas empresas públicas e privadas. Mas quando verificado frente às questões ambientais e à demanda por energia renovável, a pirólise de pneus tem chamado a atenção dos setores produtivos e gestores públicos, principalmente em cenário internacional, dedicados à geração de energia e produção de matérias-primas, a partir de processos sustentáveis (Schwalm et al., 2020).

\section{Contenção de erosão dos solos}

O processo de contenção de erosão dos solos se dá pela transformação do pneu como suporte para conter processos erosivos, utilizado principalmente em áreas de 
taludes. É realizado cortando-o ao meio durante todo o seu perímetro e separando em duas faces iguais. Essas partes são amarradas entre si, com seu interior preenchidos por solo e pedras. Nas camadas superiores os pneus ficam centralizados, colocados no centro da circunferência exatamente sobre a junção dos pneus debaixo, criando uma amarração entre todas as camadas até atingir a altura necessária (Barros e Pastor, 2019).

É uma técnica/tecnologia que está diretamente relacionado a diversas vantagens, uma vez que associa a eficiência mecânica, o baixo custo do material, minimização de rejeitos a natureza, geram economia de recursos públicos, quando considerado o baixo custo em comparação as demais modalidades de estrutura para esses locais com declives que necessitam de intervenções, pode ser construída com equipamentos considerados rudimentares e de fácil manuseio, e não demanda mão de obra especializada (Barros e Pastor, 2019).

\section{Outros usos}

Além dos diversos usos citados anteriormente, existem algumas outras utilidades menos comuns. Muitas vezes elas não são popularizadas devido ao alto custo, a ausência de tecnologia compatível ou pela ausência de mercado. Podendo serem citadas as construção de camadas de paredes através de pneus de carros para o isolamento térmico e acústico, uso de pneus reciclados para reduzir danos causados por terremotos em edificações, utilização de pneus para reduzir os impactos sonoros causados em vidraria (janelas e portas), carpete feito de pneu utilizado para reduzir impactos e barulhos em apartamentos, aparato para jardinagem, forrações termoacústicas para estúdios, pisos industriais, solados de sapato, pisos industriais e anti vibratórios intercalados por mantas de borracha, pisos para quadras poliesportivas, entre outros possíveis usos (Cajavilca et al., 2014; RECICLANIP, 2019b; Dourado et al., 2020; Oliveira et al., 2020; Vucovic, 2021).

\section{Considerações finais}

A partir desta pesquisa bibliográfica obteve-se um compilado das principais técnicas de reutilização de pneus inservíveis no Brasil, sendo possível analisar essas técnicas e também citar suas principais vantagens. Em suma, se faz necessário discorrer que o descarte inadequado de pneus tem potencialidade de comprometer negativamente $o$ meio ambiente e afetar diretamente a saúde da população através de diversos fatores. Por isso a necessidade de fiscalização das legislações existentes que contribuem para evitar essa problemática com potencial para tornar-se cada vez mais preocupante se atitudes de mudança não forem popularizadas.

No tocante ao setor empresarial, quando as empresas adotam o descarte ambientalmente correto dos pneus, adquirem diversas vantagens, onde ao longo do estudo foi possível verificar as principais vantagens correspondentes sendo possível atrelá-las a sustentabilidade.

Portanto, este ensaio visa colaborar para propagação das principais técnicas de reutilização de pneus inservíveis no Brasil, visando a sustentabilidade tão necessária a sociedade. Trabalhos como esse são relevantes não somente para a propagação de informações, mas para comprovação da eficiência de algumas técnicas. Cabe destacar, que devido a metodologia empregada neste trabalho algumas técnicas podem não ter sido elencadas, o que não descaracteriza a sua importância.

\section{Conflito de interesses}

As autoras declaram não haver conflito de interesses. 


\section{Referências}

ABNT - Associação Brasileira de Normas Técnicas. ABNT NBR 10004: Resíduos sólidos Classificação. Rio de Janeiro: ABNT, 2004.

ANIP - Associação Nacional da Indústria de Pneumáticos. Livro branco da indústria de pneus: uma política industrial para o setor. 1. ed. São Paulo: ANIP, 2015. Disponível em: <https://www.anip.com.br/arquivos/f8201-white-book-versao-final.pdf>. Acesso em: 24 jun. 2017.

Araujo, G. J. F. O coprocessamento na indústria de cimento: definição, oportunidades e vantagem competitiva. Revista Nacional de Gerenciamento de Cidades, v. 8, n. 57, p. 52-61, 2020.

Araújo, M. V. F. Coprocessamento de pneus inservíveis na indústria cimenteira. ScientiaTec: Revista de Educação, Ciência e Tecnologia do IFRS, v. 5, n. 2, p. 169-192, 2018.

Barros, A. M.; Pastor, J. S. A utilização de pneus na recuperação de encostas: vantagens econômicas, ambientais e sociais. Anais do X Fórum Internacional de Resíduos Sólidos, João Pessoa, p.1-8, 2019.

Bernardo, E. R. Reutilização dos pneus em muros de contenção de terra. Anais do VIII Congresso Luso-Moçambicano de Engenharia e V Congresso de Engenharia de Moçambique, Moçambique, INEGI/FEUP, p.953-966, 2017. Disponível em: $<$ https://paginas.fe.up.pt/clme/2017/Proceedings/data/papers/7019.pdf>. Acesso em: 25 maio 2021.

Boff, L. Sustentabilidade: o que é - o que não é. 5 ed. Petrópolis: Vozes, 2017.

Brasil. Resolução CONAMA no 499, de 6 de outubro de 2020. Dispõe sobre o licenciamento da atividade de coprocessamento de resíduos em fornos rotativos de produção de clínquer. Disponível em: <https://www.in.gov.br/en/web/dou/-/resolucaoconama/mma-n-499-de-6-de-outubro-de-2020-281790575>. Acesso em: 03 jun. 2021.

Brasil. Lei no 12.305, de 2 de agosto de 2010. Institui a Política Nacional de Resíduos Sólidos; altera a Lei no 9.605, de 12 de fevereiro de 1998; e dá outras providências. Disponível em: <http://www.planalto.gov.br/ccivil_03/_ato2007-2010/2010/lei/ 112305.htm>. Acesso em: 03 jun. 2021.

Cajavilca, E. S. R.; Rego, D. G.; Santos, A. S. Reaproveitamento de materiais para a construção civil. Cadernos de Prospecção, v. 7, $\quad$ n. 2, p. 130-134, 2014. https://doi.org/10.9771/S.CPROSP.2014.007.014

Dourado, D. C. C.; Henkes, J. A. Avaliação das propriedades físicas e mecânicas de painéis "MDP" com adição de raspas de pneu. Revista Gestão \& Sustentabilidade Ambiental, v. 9, n. 1, p. 79-95, 2020. https://doi.org/10.19177/rgsa.v9e1202079-95

Henkes, J. A.; Rodrigues, C. M. Reciclagem de pneus: atitude ambiental aliada à estratégia econômica. Revista Gestão \& Sustentabilidade Ambiental, v. 4, n. 1, p. 448-473, 2015. https://doi.org/10.19177/rgsa.v4e12015448-473

Kurz, M. N.; Brandeli, T.; Paliga, C. M.; Torres, A. Argamassa com resíduo de borracha: propriedades físicas e mecânicas. Revista Brasileira de Engenharia e Sustentabilidade, v. 5, n. 1, p. 9-16, 2018a. https://doi.org/10.15210/rbes.v5i1.12286 
Kurz, M. N.; Paliga, C. M.; Torres, A. S. Estudo do teor de substituição de agregado miúdo por resíduo de borracha em argamassa de cimento e cal. Revista Eletrônica de Engenharia Civil, v. 14, n. 2, p. 278-291, 2018b. https://doi.org/10.5216/reec.v14i2. 47555

Nerasti, A. V.; Martins, L. L. S. Reciclagem de pneumáticos: levantamento das tecnologias e legislações para a destinação final de pneus. Anais do Brazilian Technology Symposium, v. 1, p. 1-4, 2017.

Oliveira, I. D.; Spanemberg, F. E. M.; Hartwig, M. P. Desempenho do resíduo de pneu de bicicleta no isolamento térmico em sistema frio. Revista Afluente - A Revista do JPS, v. 4, n. 7, p. 7-20, 2020.

Rabelo, C. R. Análise de concreto com resíduo de pneu inservível. Anapólis: Unievangélica, 2017. (Monografia).

RECICLANIP. Missão e visão. 2019a. Disponível em: <https://www.reciclanip.org.br/ quem-somos/missao-visao-e-valores/>. Acesso em: 28 maio 2021.

RECICLANIP. Formas de destinação: principais destinações. 2019b. Disponível em: $<$ https://www.reciclanip.org.br/formas-de-destinacao/principais-destinacoes/>. Acesso em: 28 maio 2021.

Ribeiro, D.; Moura, L. S.; Pirote, N. S. S. Sustentabilidade: formas de reaproveitar os resíduos da construção civil. Revista de Ciências Gerenciais, v. 20, n. 31, p. 41-45, 2016. https://doi.org/10.17921/1415-6571.2016v20n31p41-45

Rodrigues, J. M. Mapa da motorização individual no Brasil 2019. Rio de Janeiro: Observatório das Metrópoles, 2019. Disponível em: <https://www.observatoriodas metropoles.net.br/wpcontent/uploads/2019/09/mapa_moto2019v2.pdf>. Acesso em: 25 maio 2021.

Romualdo, A. C. A.; Santos, D. E.; Castro, L. M.; Menezes, W. P.; Pasqualetto, A.; Santos, O. R. Pneus inservíveis como agregados na composição de concreto para calçadas de borracha. Anais do III International Workshop Advances in Cleaner Production-Cleaner Production Initiatives and Challenges for a Sustainable World, São Paulo, p. 18-20, 2011.

Sachs, I. Desenvolvimento sustentável: desafio do século XXI. Ambiente \& Sociedade, v. 7, n. 2, p. 214-216, 2004. https://doi.org/10.1590/S1414-753X2004000200016

Schwalm, P. C.; Rangel, N. L. S. V.; Maciel, G. P. S. Pirólise de pneus inservíveis para fins energéticos: uma revisão dos produtos de pirólise e suas aplicações. Revista Liberato, v. 21, n. 36, p. 143-158, 2020. https://doi.org/10.31514/rliberato.2020v21n36.p143

Sousa, L. F. (Org.). Relatório de pneumáticos: Resolução Conama no 416/09: 2020 (Ano base 2019). Brasília: IBAMA, 2021. Disponível em: <http://www.ibama.gov.br/ phocadownload/pneus/relatoriopneumaticos/2021-03-03- Ibama-Relatorio_

Pneumaticos_2020_completo_com_capa_terceira_versao.pdf $>$. Acesso em: 28 maio 2021.

Vucovic, N. F. Avaliação de alternativas para descarte e reuso de pneus: incorporação na massa asfáltica para produção de asfalto borracha. São José dos Campos: Universidade Federal de São Paulo, 2021. (Monografia).

Informação da Licença: Este é um artigo Open Access distribuído sob os termos da Licença Creative Commons Attribution, que permite uso irrestrito, distribuição e reprodução em qualquer meio, desde que a obra original seja devidamente citada. 